\title{
Self-assessment in Foreign Language Teaching
}

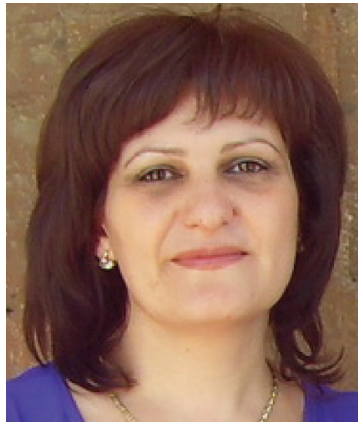

Arus Markaryan

Celf-assessment is not an alien concept to human $\checkmark$ behavior. All human beings are involved, either consciously or subconsciously, in an on-going process of selfevaluation. Until recently, however, the value of this human process was largely ignored in pedagogy. Learners were rarely asked to assess their performance.

In the last decade, with the increased attention to learnercentered curricula, needs analysis, and learner autonomy, the topic of self-assessment has become of particular interest in testing and evaluation. It is now being recognized that learners do have the ability to provide meaningful input into the assessment of their performance, and that this assessment can be valid.

Self-assessment involves students making judgments about their own work. Assessment decisions can be made by students on their own written works (essays, dictations, tests, reports), oral performances, etc. It can be extremely valuable in helping students to critique their own work and make judgments about its strengths and weaknesses.

Self-assessment has long been part of the repertoire of teachers abroad. It is recommended in many schools and universities that students submit a self-assessment with every major assignment. This is thought to be an important and valid form of assessment as (1) students create something that requires higher level thinking (i.e., they interpret their performance using definite criteria); (2) the task requires disciplined inquiry (i.e., the criteria for appraisal are derived from a specific discipline); (3) the assessment is transparent (i.e., procedures, criteria and standards are public); and (4) student have opportunities for feedback and revision during the task (Coombe 1999).

When asked why they include self-assessment in their student assessment repertoires, teachers give a variety of responses. Most frequently heard is the claim that involving students in the assessment of their work, especially giving them opportunities to contribute to the criteria on which that work will be judged, increases student engagement in assessment tasks. Closely related is the argument that this technique contributes to variety in assessment methods, a key factor in maintaining student interest and attention. Some teachers argue that self-assessment is sometimes more effective than other techniques. Still others argue that students learn more when they know that they will share responsibility for the assessment of what they have learned (Ross 2005).

Students can become better language learners when they reflect upon what they are learning and how they are learning it. In this kind of reflection, students step back from the learning process to think about their language learning strategies and their progress as language learners. This encourages students to become independent learners and can increase their motivation.

Most students prefer self-assessment to assessment by the teacher alone. The reasons they give suggest additional benefits of self-assessment: 1) students say that when using 
this technique they have a better understanding of what they are supposed to do because they are involved in setting the criteria for the assessment; 2) students argue that selfassessment is fairer because it enables them to include important performance dimensions such as effort, that is not usually included in their grade; 3) self-assessment enables them to communicate information about their performance (e.g., their goals and reasoning) that is not otherwise available to their teacher; 4) it gives them information they can use to improve their work (Ross 2005).

Even though students prefer self-assessment to teacher appraisal alone, such participation is more work for students. Some may find it boring and argue that it is unfair to ask them to do the teacher's job. Teachers express concern about the lack of student commitment to the process arguing that self-assessment will not work if students do not put the required effort into it.

Only a very small proportion of school and university teachers in our country report using self-assessment, because they have doubts about the value and accuracy of student self-appraisals. The doubts center on the concern that students may have inflated perceptions of their accomplishments and that they may be motivated by self-interest. Frequently heard is the claim that the "good students" under-estimate their achievement, while others who do not know what successful performance requires or wish to have higher grades, over-estimate their achievements. This may be the reason why self-assessment or rather self-correction, is used for teaching purposes only and the marks the students give themselves do not affect their final grades. No student would ever be asked to assess their mid-term or final tests whose results form their final credits.

However, teachers shouldn't ignore the benefits of self-assessment. It is actually an effective way of correction. Correcting is a waste of time and serves little purpose if it makes no impact, if the students fail to notice and understand the correction.

Self-assessment encourages students to focus on their achievements, rather than comparisons to other students. When students correct and assess their own work their attention focuses on the mistakes they have made. When the teacher assesses their work they focus on their own and their peers' marks. They are more interested in comparing the results than in analysing and correcting their mistakes and improving their knowledge. An important advantage is that self-assessment reduces the teachers' workload.

To make self-assessment more valid and reliable teachers need to provide their students with distinct assessment criteria, e.g. an answer key to the test, a photocopy of the dictated text, a photocopy of the Teacher's Book key, etc. It will be more helpful if the students take part in constructing the key. After the students are through with the test, the teacher can discuss it with the class, explain all the items. Meanwhile the students put down the correct answers and thus make up the correction criteria to use them in the assessment of their work.

Assessing their own dictation or self-dictation is a useful way for the students to revise and retain spelling rules.

Advanced students can assess their essays and reproductions. To gain better results teachers can use a partial correction technique. They can first read the works themselves, underline or circle the parts that contain mistakes, and hand the works back to the stu- 
dents to correct and assess them. To be able to carry out this task the students will have to do a lot of revising and textbook and dictionary consulting, which is undoubtedly beneficial to the learning process. It will encourage them to see writing as a process not a product and make them look back at their work and see it as a draft to improve, rather than just a final "product" to be corrected and marked.

A good idea might be asking the students "to confess" their mistakes, i.e. to tell their peers what mistakes they have made and in this way prevent themselves and others from repeating them.

We hope that when the main concern of students becomes acquiring knowledge rather than high grades, self-assessment can be used more efficiently in high schools, not only for teaching purposes but for evaluation as well.

\section{References:}

1. Coombe, C. (1999) Self-Assessment in Language Testing: Reliability and Validity Issues. // Assessment, Research \& Evaluation. TESOL Arabia Newsletter, Vol. 7 (1:7-8). www3.telus.net/linguisticsissues/selfassess.

2. Liang, J. (2006) Overview of Self-Assessment in the Second Language Writing Classroom. // Paper presented at the 2006 TESOL Convention. Florida: Tampa.

3. Noonan, B. Duncan, C.R. (2006) Peer and Self-Assessment in High Schools. // Practical Assessment, Research \& Evaluation. A peer-reviewed electronic journal. Vol. 10 (17). www.p21.org/route21/index.php?option=com

4. Oskarsson, M. (1980) Approaches to Self-Assessment in Foreign Language Learning. Oxford: Oxford University Press.

5. Ross, J. A. (2005) The Reliability, Validity, and Utility of Self-Assessment. I/ Practical Assessment, Research \& Evaluation. A peer-reviewed electronic journal. Vol. 15 (10). pareonline.net/pdf/v11n10.

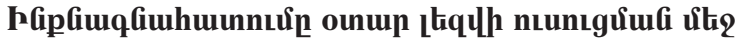

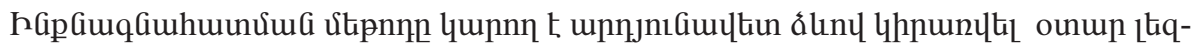

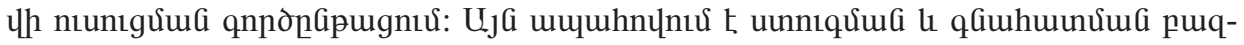

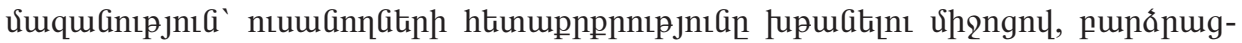

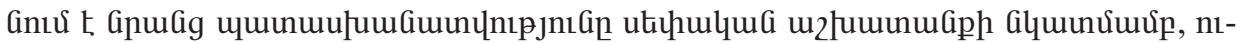

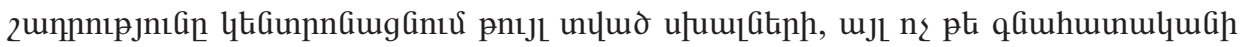

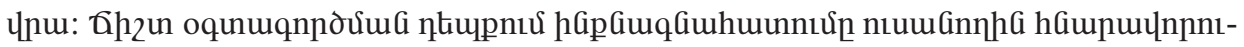

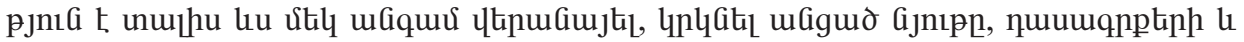

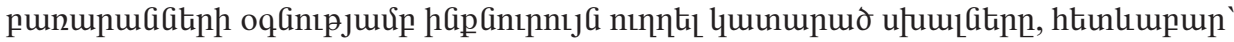

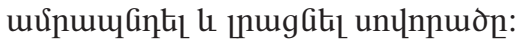

